\title{
Prosocial Cartoons Exposure and Aggressive Behavior in Aggressive Boys: The Potential Mediating Role of Empathy
}

Qian Zhang ( $\sim$ zhq@swu.edu.cn )

Southwest University

Yi Cao

Southwest University

\section{Research Article}

Keywords: prosocial cartoons, aggressive behavior, empathy, aggressive boys

Posted Date: January 21st, 2021

DOl: https://doi.org/10.21203/rs.3.rs-149348/v1

License: (c) (1) This work is licensed under a Creative Commons Attribution 4.0 International License.

Read Full License 


\section{Abstract}

Given that evidence for positive effects of cartoons has been relatively sparse, this article reports an experimental study concerning the effects of prosocial cartoons on aggressive behavior among aggressive boys $\left(n=160 ; M_{\text {age }}=8.00, S D=2.01\right)$, a population that has received relatively little attention in research literature. Boys were nominated by teachers as aggressive from three Chinese kindergartens and three primary schools. Cartoons were assessed as prosocial or nonprosocial via 100 experts, then half of them were randomly assigned to watch either prosocial cartoons or matched nonprosocial cartoons (a randomized controlled experiment). Boys in each condition watched the assigned one cartoon for 15 minutes per day and five different cartoons per week. Basic Empathy Scale (BES) and Competitive Reaction Time Task (CRTT) were employed to measure levels of empathy and aggressive behavior. Results showed that aggressive boys who watched prosocial cartoons reported higher levels of empathy but less aggressive behavior than those who watched nonprosocial cartoons. Specifically, tenyear-old boys reported higher levels of empathy and less aggressive behavior than six-year-old boys in the prosocial cartoon condition. The relationship between prosocial cartoons viewed and aggressive behavior was mediated by increased empathy (especially 10-year-old aggressive boys). The aggression reducing effect of prosocial cartoons indicated that training aggressive boys to be empathetic could decrease their aggression levels in educational practice.

\section{Introduction}

The effect of prosocial cartoons on childhood aggression is a much-needed research topic, and this study attempts to broaden the research by studying Eastern cultures to contribute to extant literature that has been primarily focused on Western cultures as of late. Aggression refers to any kind of externalized behavior directed toward another person that is carried out with the proximate intent to cause harm, and the target is motivated to avoid this behavior (Anderson \& Bushman, 2002; Geen, 2001). Laboratory experiments usually used proxy or artificial measures of aggression (e.g., loud noise blasts, spicy hot sauce given to a partner, ratio of weapon toy time to total time, preventing a partner from earning money) for ethical reasons. In the present study, aggressive behavior is defined as the noise intensity boys set for virtual opponents in the competitive reaction time task (CRTT), which has been widely accepted as a labbased paradigm to measure aggressive behavior (Konzok et al., 2020; Warburton \& Bushman, 2019). Therefore, the noise intensity participants select for their opponents are recorded (CRTT scores), with a higher level of noise intensity being indicative of stronger aggressive behavior.

\subsection{General Learning Model}

The General Learning Model (GLM) posits that input variables (personal vs. situational) elicit behavioral outcomes through a person's internal state, such as cognition, affect, and arousal (Buckley \& Anderson, 2006). Moreover, the GLM suggests that depending on the content of the media exposed, either negative or positive effects of video game exposure on social behavior are to be expected. For instance, whereas 
exposure to violent media should increase aggression, exposure to prosocial media is assumed to decrease aggression. Importantly, each prosocial media exposure is a learning trial, which, in turn, can lead to well-rehearsed learning structure and increase prosocial behavior. Usually, a GLM is presented to explain how media exposure can produce desirable learning outcomes, such as prosocial behavior, they also can produce undesirable outcomes, such as increased aggressive behavior. In the present study, the GLM is used as the theoretical framework to explain the effects of prosocial vs. nonprosocial cartoons on aggressive behavior.

\subsection{Prosocial media and aggressive behavior}

Although abundance of studies have documented a negative effect of violent media on aggressive behavior in children and adolescents, such as cartoon violence (e.g., Kirsh, 2006), game violence (Prescott, Sargent, \& Hull, 2018), movie violence (Dillon \& Bushman, 2017), the relationship between prosocial media use and children's aggression was relatively few in China. Notably, children may be confused with aggressive heroes and learn moral messages from television characters. In this study, prosocial cartoons, as a typical prosocial-media, include a battery of prosocial content and scenes (e.g., donation, cooperation, sharing, help, comfort). Notably, previous literature suggested that boys show more physical aggression than girls (e.g., Konzok et al., 2020; Teng et al., 2020). Also, aggressive boys have their own unique attributional styles (Bickett, Milich, \& Brown, 1996; Graham, Weiner, \& BeneshWeiner, 1995). More specifically, the correlation between relational aggressive behavior and negative nomination, social preference, social impact, peer rating of Chinese boys is stronger than that of girls (Qin, 2004; Tan, 2005; Zhang, 2016). Thus, aggressive behavior in young aggressive boys is an important topic, which should be appreciated and highlighted. In particular, past research based on the General Learning Model (GLM) has provided abundant evidence that short-term and long-term exposure to prosocial-media (e.g., video games, cartoons, music) decrease aggressive tendencies and increase prosocial tendencies (Gentile et al., 2009; Greitemeyer, 2011, 2009; Greitemeyer, Agthe, Turner, \& Gschwendtner, 2012; Greitemeyer \& Mügge, 2014; Greitemeyer \& Osswald, 2009, 2010; Greitemeyer, Osswald, \& Brauer, 2010; Kennedy, 2013; Prot et al., 2014; Whitaker \& Bushman, 2012). On the basis of GLM and previous findings, it is possible that prosocial cartoon viewing is negatively associated with aggressive behavior.

\subsection{Age and aggressive behavior}

Age is negatively linked to physical aggression, with younger children being more aggressive than older children (Bukowski, 1990). It is possible that young children are more vulnerable to media violence effects than adults (Gentile, Li, Khoo, Prot, \& Anderson, 2014; Prot et al., 2014; Zhao, 2018) and cartoon violence has a potential impact on the age development of aggression (Kirsh, 2006). Theoretically, screen violence can have a greater impact on older children than younger children in a short-term experimental context because the knowledge structure of older children is more stable than that of younger children and 
therefore more easily primed (Bushman \& Huesmann, 2006). Thus, older children are less likely to display aggressive tendencies compared to younger children immediately after viewing prosocial cartoons. On the contrary, other research findings have not found significant age effects in screen violence effects (e.g., Tear \& Nielsen, 2014). In this sense, it is necessary to test the age effects on aggressive behavior under the condition of prosocial cartoons among aggressive boys.

\subsection{Empathy and aggressive behavior}

Empathy is an ability to vicariously recognize and understand the feelings of other people by putting oneself in others' position, which has been proved to be a crucial mediator of media effects (Bartholow, Sestir, \& Davis, 2005; Calvert, Strouse, \& Murray, 2006; Zhen et al., 2011) and a critical facilitator of prosocial behavior by making them more sympathetic and helpful (Lockwood \& Viding, 2016). More specifically, empathy includes dimensions of cognitive empathy and affective empathy (Cuff, Brown, Taylor, \& Howat, 2016). It is worth noting that increased empathy promotes altruistic behavior (Klimecki et al., 2016). Importantly, the research literature has shown that individuals with high trait empathy actively oppose unjustified violent behavior (Hartmann, Toz, \& Brandon, 2010). Also, empathy can be treated as a protective factor which mediates the media effects on individuals and can weaken the negative media effects (Anderson et al., 2010; Miller \& Eisenberg, 1988; Zhen et al., 2011). Notably, there is a debate about the relationship between media exposure and empathy and aggression (Decety, Echols, \& Correll, 2010; Gao et al., 2017; Hilgard, Engelhardt, \& Rouder, 2017; Kepes, Bushman, \& Anderson, 2017; Miller \& Eisenberg, 1988; Szycik et al., 2017). To remedy this defect, the present study concerns the effect of the prosocial attributes of cartoons and that of empathy on aggressive boys. Importantly, the study examines the mediating effect of empathy on aggressive behavior specifically by inducing empathy after prosocial cartoons exposure.

\subsection{The present experiment}

Overall, the study attempts to examine the effect of prosocial cartoon exposure on aggressive behavior in aggressive boys, and whether a protective factor (i.e., empathy) mediates this effect in order to provide intervention and prevention measures for aggressive behavior. The purpose of this experiment was threefold: (a) to compare levels of empathy and aggressive behavior of aggressive boys when exposure to prosocial or nonprosocial cartoons, (b) to examine how aggressive behavior using different cartoons differs by age (6 years vs. 10 years) during childhood, and (c) to test the potential mediating mechanism of empathy for aggressive behavior after prosocial cartoon exposure. In doing so, we attempt to conduct an experiment with a 2 (cartoon) $\times 2$ (age) design to achieve the above research goals. Thus, the following hypotheses were stated.

H1: Repeated exposure to prosocial cartoons will decrease aggressive behavior among aggressive boys over time. 
H2: Ten-year-old boys will report less aggressive behavior than six-year-old boys after prosocial cartoon exposure.

H3: Empathy will mediate the effects of prosocial cartoons on aggressive behavior.

\section{Method}

\subsection{Participants}

In Fall semester of 2019, a total of 160 aggressive boys $\left(M_{\mathrm{age}}=8.00, S D=2.01\right)$ were recruited from three Chinese kindergartens and three primary schools based on teacher nomination. Specifically, each teacher nominated the top 4 aggressive boys in their class. 80 participants were randomly assigned to watch five prosocial cartoons for consecutive 5 days (treatment group), and the other 80 participants were randomly assigned to watch five nonprosocial cartoons for consecutive 5 days (control group). They watched one assigned cartoon for 15 minutes per day and totally five cartoons per week. Given that males show more physical aggression than females in childhood (Archer, 2009; Anderson, Buckley, \& Carnagey, 2008; Boyle, Connolly, \& Hainey, 2011; Smith \& Waterman, 2005; Toldos, 2010), and that the perpetrators and victims of physical and social aggression are often children rather than adults in television cartoons (Luther \& Legg, 2010), this study only recruited aggressive boys as participants. No participants failed to complete the experiment. In this study, we report all measures, manipulations and exclusions. Sample size was determined before any data analysis, and no data collection was continued after data analysis.

\subsection{Design}

The design of the study was experimental, with cartoon and age as independent variables. Empathy and aggressive behavior (CRTT scores) was the outcome variable. To this end, a 2 (cartoon: prosocial vs. nonprosocial) $\times 2$ (age: 6 year olds vs. 10 year olds) experimental-control design was conducted.

\subsection{The prosocial cartoons}

Prosocial cartoons refer to a type of cartoons that attempt to teach moral messages in comparison with standard/nonprosocial cartoons in televised programs (Liss \& Reinhardt, 1980). Ten types of cartoons, including Handy Manny (USA/Canada), Peppa Pig (UK), PAW Patrol (USA), Boonie Bears (China), BigHeaded Kid and Small-Headed Father (China), Travel Notes of Caravan (Russia), Piny (USA), Moon Ring (China), Doraemon (Japan), and Cute Chicken (China), were used as materials in this experiment. Handy Manny tells a story of Manny and his magical tools can help others to solve problems. Peppa Pig tells the a story of happy life for Peppa pig and her family member (i.e., father, mother, brother). PAW Patrol tells a story of a ten-year-old boy named Ryder who organizes the PAW patrol team consisted of dogs to repair Mayor Goodway's boat to help him win the race. Boonie Bears tells a story of two bears named Briar and Bramble help a human logger name Vick to catch train to go home and celebrate the Chinese lunar New Year. Big-Headed Kid and Small-Headed Father tells a story of big-headed son and his small-headed father setting up a small animal protection team to save wild animals. The above five cartoons include prosocial contents and scenes. 
Travel Notes of Caravan includes episodes of Spaskota and Mongolian Yurts. Spassky Tower tells a story of introduction between Spaskota and Caravan in a leisure game. Mongolian Yurts tells a story that Gary is curious about how the Yurt travels without wheels, so he goes to find the yurt. After finding the Yurt, Yurt introduced himself to Gerry. Piny tells the story of a humble 14-year-old designer (Michelle Fairchild) who is interested in fashion and has the dream of becoming a figure in the "fashion world", thus launching an interesting and creative competition story. Moon Ring tells the story of Xiaoyue and Filo, two magic maidens, who fight against the dark forces in order to save their companion Meixing. Doraemon tells a story that Doraemon cleans the bag and puts it out of the window to dry. Nobita is ready to go out to play happily, but his mother does not allow him to go out to play. He must do his homework well. Nobita wants to take any door out of the bag to help him with his homework. Cute Chicken Team tells a story that the chickens play Hide and Seek together. They have a good time. They play games with the bamboo insects and caterpillars on the trees. The above five cartoons include few prosocial contents and scenes. All the cartoons are voiced in Mandarin.

Based on the appropriate length of media effects (Barlett, Branch, Rodeheffer, \& Harris, 2009; Gentile, Bender, \& Anderson, 2017; Hemovich, 2020), the time of each cartoon were limited to 15 minutes. In particular, to guarantee the the selected cartoons have prosocial attributes, 100 experts, including 60 undergraduates, 20 postgraduates, 10 kindergarten teachers and 10 parents $\left(M_{\text {age }}=24.17, S D=6.22 ; 50 \%\right.$ females), were invited to assess the prosocial attributes of the ten cartoons using a 5-point Likert-type scale ( 1 = not consistent at all, 5 = very consistent) according to the following indices: (1) Prosocial Content, (2) Prosocial Image, (3) Engaging, (4) Boring, (5) Joyful, (6) Easy, and (7) Frustrated. Each ten raters watched a type of cartoon, constituting for 10 rating groups. In the present study, cartoons with a total average rating score more than 3 points are deemed as prosocial cartoons, whilst cartoons with a total average rating score less than 3 points are deemed as nonprosocial cartoons.

Given that content and image can be considered as the main feature of media violence (Adachi \& Willoughby, 2011), we conduct manipulation check to test cartoons as prosocial or nonprosocial based on image and content accordingly. The sequence (from high to low) of the ten cartoons are the following: (1) Handy Manny $\left(M_{\text {image }}=4.10, S D=0.57 ; M_{\text {content }}=4.50, S D=0.53\right)$, (2) Big-Headed Kid and SmallHeaded Father $\left(M_{\text {image }}=4.20, S D=1.03 ; M_{\text {content }}=4.00, S D=0.94\right)$, (3) Boonie Bears $\left(M_{\text {image }}=4.20, S D=\right.$ 0.79; $\left.M_{\text {content }}=4.00, S D=1.05\right)$, (4) Peppa Pig $\left(M_{\text {image }}=4.40, S D=0.70 ; M_{\text {content }}=4.40, S D=0.70\right)$, (5) PAW Patrol $\left(M_{\text {image }}=3.80, S D=1.23 ; M_{\text {content }}=4.80, S D=0.42\right)$, (6) Travel Notes of Caravan $\left(M_{\text {image }}=\right.$ $\left.2.40, S D=1.26 ; M_{\text {content }}=2.60, S D=1.17\right)$, (7) Piny $\left(M_{\text {image }}=2.10, S D=0.99 ; M_{\text {content }}=2.40, S D=1.07\right)$, (8) Moon Ring $\left(M_{\text {image }}=2.10, S D=1.10 ; M_{\text {content }}=1.80, S D=0.79\right)$, (9) Doraemon $\left(M_{\text {image }}=2.40, S D=\right.$ $\left.1.07 ; M_{\text {content }}=1.80, S D=1.03\right)$, and finally (10) Cute Chicken $\left(M_{\text {image }}=1.80, S D=1.03 ; M_{\text {content }}=1.90\right.$, $S D=0.88)$. Most importantly, the rating score of Violent Content $[F(9,90)=19.01, p<0.001, d=0.88]$ and Violent Image $[F(9,90)=11.35, p<0.001, d=0.68]$ were significant. However, no significant rating differences were found in terms of Engaging $[F(9,90)=1.56, p=0.14, d=0.25]$, Boring $[F(9,90)=0.72, p=$ $0.69, d=0.17]$, Joyful $[F(9,90)=1.29, p=0.26, d=0.23]$, Easy $[F(9,90)=1.09, p=0.38, d=0.21]$, and Frustrated $[F(9,90)=0.94, p=0.50, d=0.20]$. Given that ratings of content and image were more than 3 
points for Handy Manny, Peppa Pig, PAW Patrol, Boonie Bears, and Big-Headed Kid and Small-Headed Father, these five cartoons were selected as prosocial cartoons. Given that ratings of content and image were less than 3 points for Travel Notes of Caravan, Piny, Moon Ring, Doraemon, and Cute Chicken, these five cartoons were selected as nonprosocial cartoons. Therefore, we regarded the ten cartoons to be appropriate experimental materials. To assure that the cartoons used for the experimental manipulation and extendable to the entire category of prosocial cartoons. In order to generalize the results, we have adopted five cartoons per type of cartoon (i.e. five different exemplars of prosocial cartoons, vs. 5 different exemplars of nonprosocial/neutral cartoons).

\subsection{Empathy}

Basic Empathy Scale (BES), a 20-item Likert 5-point scale, was used to measure the level of empathy (Jolliffe \& Farrington, 2006). The BES consists of two subscales of Affective Empathy (AE) and Cognitive Empathy (CE). The AE, including 11 items, measures emotional congruence with another person's emotions, while the $C E$, including 9 items, measures ability to understand another person's feelings. Each item asks boys to orally respond on a 5-point Likert scale anchored from 1 ("strongly disagree") to 5 ("strongly agree") The Cronbach a of AE subscale (11 items) is 0.85 , and the CE subscale (9 items) is 0.79 . In the present study, two subscales cores were calculated for each participant by summing their item scores. The overall measure of BES was internally consistent (Cronbach $a=0.86$ ). The Cronbach $a$ of $A E$ and CE is 0.77 and 0.63 , respectively. The higher empathy score is indicative of higher levels of empathy in aggressive boys, and vice versa.

\subsection{Aggressive behavior}

The competitive reaction time task (CRTT), a scientific and flexible aggression paradigm, was proved by recent researchers as a valid measure of laboratory aggression (Konzok et al., 2020). In the CRTT, each boy competed with a "virtual opponent" to see who could respond faster to a presentation of a tone. After each trial, the "loser" received a painful and loud noise set by the opponent as a punishment. The pattern of wins/losses and the noise intensity imposed upon by the participant on "lose" trials were predetermined. They were informed that they would have no contact with "virtual opponents" during and after the experiment.

The CRTT includes a two-step process. Participants are given sample noise blasts of $70 \mathrm{~dB}$ (decibel) and $100 \mathrm{db}$ prior to Step 1. A noise of $100 \mathrm{db}$ is similar to having someone come right up to your ear and scream as loudly as he can. It tends to make people flinch away from it. Step 1 consists of 25 trials in which the "virtual opponent" sets the noise intensity level for the boys on "lose" trials. In Step 1, all participants receive a same random pattern of 13 wins and 12 losses, which is typical in such studies. Trial 1 is a "loss" and Trial 25 is a "win" (the first trial is lost by the participant in order to have an index of provoked aggression in the second trial). The remaining 24 trials are divided into three blocks of 8 . The first and the second block had 4 wins and 4 losses while the third block had 5 wins and 3 losses. The last trial is always a "win". The noise intensities set by the virtual opponents for participants range from 70 to $100 \mathrm{~dB}$ (low to high). The participants see the intensity of noise supposedly set by the opponent on each 
trial even if they "won" that trial. At the end of Step 1, the assistant reminds children that in Step 2 they will be the ones setting the noise intensity level for their opponents. A no noise setting option $(0 \mathrm{~dB}=$ no aggressive behavior) is also available for participants. Step 2 is identical, except that the roles are reversed. The noise intensity (70-100 dB) participants set for the virtual opponent is represented as a measure of aggressive behavior across the 25 trials (e.g., 13 wins vs. 12 losses) in Step 2. The higher noise intensity setting (CRTT scores) is indicative of more aggressive behavior in aggressive boys, and vice versa.

\subsection{Procedure}

The study was approved by the Ethics Committee of Southwest University in China and was in line with the 1964 Helsinki declaration or comparable ethical standards. The cover story is the following: All participants were told that the study was being conducted anonymously and that their information would remain confidential. Each participant was voluntary and could withdraw from the study at any time during five consecutive days of cartoon viewing. Participants sat in front of laptops and signed consent forms with the help of the trained assistants in a quiet big room at kindergartens or schools. Their parents also gave consents. They were then told that the experiment examined the effects of cartoon exposure on noise intensity settings. They were instructed how to make responses to the presented tone and set noise intensity for opponents. We used the CRTT to measure the pretest levels of aggressive behavior for all participants. Then they watched their assigned cartoon for 15 minutes per day for consecutive five days. Afterward, a 20-item BES that was administered before the CRTT after the participants watched the fifth cartoon. Participants were debriefed about their empathy and completed the CRTT. Given that suspicion might be a problem in CRTT (e.g., Anderson, Anderson, \& Deuser, 1996), lab assistants evaluated suspicion by conducting an interview with each participant as part of the debriefing process. In particular, no participants expressed suspicion during the debriefing. The assistants explained all procedures, answered questions, and thanked the participants for their support.

\subsection{Data analysis}

Descriptive statistics, two-way ANOVA were conducted using SPSS 21.0. The mediation analyses was performed using PROCESS 3.0 (Hayes, 2013). The bootstrapping method, which could attain robust standard errors for parameter estimation, was used to test the significance of the mediating effect using Model 4 . We set 5,000 bootstrapping samples and $95 \%$ bias-corrected confidence intervals (Cl). The analysis had $80 \%$ power to detect an effect size of [d-value and part. $\eta^{2}$ ].

\section{Results}

\subsection{Pretest levels of aggression}

An independent sample t-test was performed to compare differences in baseline levels of aggression between the treatment and the control group. Overall, there were no significant differences in pretest levels of aggression between the two groups $[t(158)=-0.16, p=0.87, d=-0.03 ; M=92.31(S D=2.72)$ 
versus $M=92.38(S D=2.66)$ ]. Similarly, there were no significant levels of aggression between 6 year olds and 10 year olds at baseline $[t(158)=0.79, p=0.43, d=0.13 ; M=92.51(S D=2.58)$ versus $M=92.17(S D=$ 2.79)]. While this may seem surprising at first glance, recall that we chose a sample of boys who were more aggressive.

\subsection{Descriptive statistics}

Tables 1 and 2 list the means, standard deviations and cell sample sizes of empathy and aggressive behavior under 4 conditions. The mean level of empathy was higher for the prosocial group than the nonprosocial group. Watching prosocial cartoons resulted in higher empathy scores than watching nonprosocial cartoons. As for age, 6-year-old boys' mean level of empathy was lower than that of 10-yearold boys in the prosocial cartoon condition. The mean level of aggressive behavior was lower for the prosocial group than for the nonprosocial group. Watching prosocial cartoons resulted in less aggressive behavior when setting noise intensity than watching nonprosocial cartoons. As for age, 6-year-old boys' mean level of aggressive behavior was higher than that of 10-year-old boys in the prosocial cartoon condition. Thus, prosocial cartoons, age, empathy and aggressive behavior may have a certain relationship. Next, we conducted a specific analysis of these variables.

Table 1

Means and standard deviations for empathy.

\begin{tabular}{|lllll|}
\hline Age & $\begin{array}{l}\text { Prosocial } \\
\text { M+ } \boldsymbol{S} \boldsymbol{D}\end{array}$ & $\boldsymbol{N}$ & $\begin{array}{l}\text { Nonprosocial } \\
\boldsymbol{M}+\boldsymbol{S} \boldsymbol{D}\end{array}$ & $\boldsymbol{N}$ \\
\hline 6 years & $2.74+0.36$ & 40 & $2.71+0.50$ & 40 \\
10 years & $3.04+0.51$ & 40 & $2.66+0.52$ & 40 \\
Total & $2.89+0.46$ & 80 & $2.68+0.51$ & 80 \\
\hline
\end{tabular}

Table 2

Means and standard deviations for aggressive behavior in a CRTT (in dB).

\begin{tabular}{|c|c|c|c|c|}
\hline Age & $\begin{array}{l}\text { Prosocial } \\
M+S D\end{array}$ & $N$ & $\begin{array}{l}\text { Nonprosocial } \\
M+S D\end{array}$ & $N$ \\
\hline 6 years & $79.21+8.26$ & 40 & $79.23+12.61$ & 40 \\
\hline 10 years & $73.90+8.83$ & 40 & $83.02+11.08$ & 40 \\
\hline Total & $76.56+8.91$ & 80 & $81.13+11.95$ & 80 \\
\hline
\end{tabular}

\subsection{Analysis of variance on levels of empathy}


The main effect of cartoon on empathy was significant. Aggressive boys exposed to prosocial cartoons reported higher empathy than those exposed to nonprosocial cartoons $[F(1,156)=7.40, p=0.007, d=$ 0.43 , part. $\eta^{2}=0.04 ; M=2.89(S D=0.05)>2.68(S D=0.05)$ ]. However, the main effect of age on empathy was not significant $\left[F(1,156)=2.89, p=0.09, d=0.27\right.$, part. $\left.\eta^{2}=0.02\right]$. The cartoon $\mathrm{x}$ age interaction on empathy was significant $\left[F(1,156)=5.03, p=0.03, d=0.36\right.$, part. $\left.\eta^{2}=0.03\right]$. A simple effect analysis demonstrated that the group of 10-year-old aggressive boys reported higher empathy than the group of 6year-old aggressive boys in the prosocial cartoon condition $\left[F(1,156)=7.77, p=0.006, d=0.44\right.$, part. $\eta^{2}=$ $0.05 ; M=3.04(S D=0.08)>2.74(S D=0.08)$ ], but no significant age effects were found in the nonprosocial cartoon condition $\left[F(1,156)=0.15, p=0.70, d=0.06\right.$, part. $\left.\eta^{2}=0.001\right]$ ( Fig. 1).

\subsection{Analysis of variance on aggressive behavior}

The main effect of cartoon on aggressive behavior (CRTT scores) was significant. Boys exposed to prosocial cartoons reported lower CRTT scores than those exposed to nonprosocial cartoons $[F(1,156)=$ $7.80, p=0.006, d=0.44$, part. $\left.\eta^{2}=0.05 ; M=76.56(S D=1.16)<86.13(S D=1.16)\right]$. However, the main effect of age on CRTT scores was not significant $\left[F(1,156)=0.22, p=0.64, d=0.08\right.$, part. $\left.\eta^{2}=0.001\right]$. The cartoon $\mathrm{x}$ age interaction on CRTT scores was significant $\left[F(1,156)=7.74, p=0.006, d=0.44\right.$, part. $\eta^{2}=$ 0.05]. A simple effect analysis demonstrated that 6-year-old aggressive boys reported higher CRTT scores than 10-year-old aggressive boys in the prosocial cartoon condition $[F(1,156)=5.27, p=0.02, d=0.37$, part. $\left.\eta^{2}=0.03 ; M=79.21(S D=1.64)>73.90(S D=1.64)\right]$, but no significant age effects were found in the nonprosocial cartoon condition $\left[F(1,156)=2.68, p=0.10, d=0.26\right.$, part. $\left.\eta^{2}=0.02\right]$ (Fig. 2).

\subsection{Empathy as a potential mediator of aggressive behavior}

Since prosocial cartoon viewing increases levels of empathy and decreases aggressive behavior successively, and we attempt to test the $\mathrm{H} 3$ that empathy would mediate the effects of prosocial cartoons on aggressive behavior. Meanwhile, given that a small but noticeable correlation between empathy and aggressive behavior $[r=-0.41, p<0.001]$, empathy is a likely mediation candidate. Thus, we ran a mediation analysis by using the PROCESS 3.0 macro Model 4 of SPSS 21.0 with all data standardized. In this model, empathy was a mediator, cartoon was the predictor, CRTT was the outcome. Age was included as a covariate because of significant cartoon $\mathrm{x}$ age interaction in ANOVA results.

As can be seen from Fig. 3, the direct effect of prosocial cartoons on aggressive behavior was not significant $(\beta=-0.13 ; S E=0.07 ; 95 \% \mathrm{Cl}=[-0.28,0.01])$. Prosocial cartoons positively predicted empathy $(\beta$ $=0.21 ; S E=0.08 ; 95 \% \mathrm{Cl}=[0.06,0.36])$. Empathy negatively predicted aggressive behavior $(\beta=-0.39 ; S E=$ $0.07 ; 95 \% \mathrm{Cl}=[-0.53,-0.24])$. Thus, empathy wholly mediated the prosocial cartoon effects on aggressive behavior $(\beta=-0.08 ; S E=0.04 ; 95 \% \mathrm{Cl}=[-0.16,-0.02]$. The results supported the validity of the CRTT by demonstrating that the noise intensity set by aggressive boys was based on levels of empathy to harm the virtual opponents. 
Specifically, we assessed whether empathy mediated the prosocial cartoon effects on aggression for 10year-old aggressive boys and 6-year-old aggressive boys in a separate mediation model. As shown in Fig. 4 , the direct of prosocial cartoons on aggressive behavior was significant for 10-year-old aggressive boys $(\beta=-0.26 ; S E=0.10 ; 95 \% \mathrm{Cl}=[-0.45,-0.06])$, but not for 6 -year-old aggressive boys $(\beta=0.008 ; S E=$ $0.11 ; 95 \% \mathrm{Cl}=[-0.21,0.23])$. Prosocial cartoons positively predicted empathy for 10 -year-old aggressive boys $(\beta=0.38 ; S E=0.12 ; 95 \% \mathrm{Cl}=[0.15,0.61])$, but not for 6 -year-old aggressive boys $(\beta=0.04 ; S E=0.10$; $95 \% \mathrm{Cl}=[-0.16,0.23])$. Empathy negatively predicted aggressive behavior for 10 -year-old aggressive boys $(\beta=-0.44 ; S E=0.09 ; 95 \% \mathrm{Cl}=[-0.62,-0.26])$, but not for 6 -year-old aggressive boys $(\beta=-0.24 ; S E=0.13$; $95 \% \mathrm{Cl}=[-0.49,0.005])$. The mediating effect of prosocial cartoons on aggressive behavior through empathy was partially significant for 10-year-old aggressive boys $(\beta=-0.17 ; S E=0.07 ; 95 \% \mathrm{Cl}=[-0.31$, $-0.06])$, but not for 6-year-old aggressive boys $(\beta=-0.009 ; S E=0.03 ; 95 \% \mathrm{Cl}=[-0.06,0.05])$.

\section{Discussion}

\subsection{Repeated exposure to prosocial cartoons reduces aggression over time}

The pretest levels of aggression were not significant between treatment group and control group, suggesting all boys have high but non-significant aggression differences. Also, the pretest levels of aggression were not significant between 6 year olds and 10 year olds, suggesting age effects on aggression were not significant at the pretest level. Thus, we can postulate that the baseline levels of aggression among all participants were homogeneous. The post-test results indicated that aggressive behaviors among aggressive boys are attenuated under conditions of prosocial cartoons (versus nonprosocial), which confirmed $\mathrm{H} 1$ that repeated exposure to prosocial cartoons would decrease aggressive behavior among aggressive boys based on the homogeneous pretest levels of aggression between the treatment group and the control group. More specifically, less aggressive behaviors are emerging among boys in the prosocial cartoon condition than those in the nonprosocial cartoon condition, which is consistent with previous findings that prosocial-media exposure reduces children's aggression in comparison with standard-media programs (Greitemeyer, 2011; Greitemeyer, Agthe, Turner, \& Gschwendtner, 2012; Greitemeyer \& Mügge, 2014; Greitemeyer \& Osswald, 2009; Liss \& Reinhardt, 1980; Saleem, Anderson, \& Gentile, 2012; Prot et al., 2014). Generally, aggressive boys demonstrate a bias toward attributing hostility to peers in unwarranted circumstances (Dodge \& Newman, 1981). Our findings are consistent with the social-cognitive models of aggressive behavior such as the GLM (Buckley \& Anderson, 2006).

Why do prosocial cartoons decrease aggressive behavior? This may be explained as the following reasons. On the one hand, the cartoon characters used in this study are famous. Researchers have found that there is a strong effect with well-known media characters, which viewers tend to identify with and imitate (Calvert, Murray, \& Conger, 2004), and it is easy for individuals to predict a game character's 
behavior and behave similarly when playing a famous role (Bargh, Chen, \& Burrows, 1996). On the other hand, prosocial media characters (e.g., justice behavior) can evoke altruism emotionally in children (Farsides, Pettman, \& Tourle, 2013; Funk, Baldacci, Pasold, \& Baumgardner, 2004). Given that the pretest levels of aggression were not significant between treatment group and the control group, it can be concluded that watching prosocial cartoons (versus nonprosocial) leads to lower level of aggression.

\subsection{Ten-year-old boys report less aggressive behavior than six-year-old boys after prosocial cartoons exposure}

Consistent with $\mathrm{H} 2$, namely that 10 year old boys exposed to prosocial cartoons show higher empathetic intentions and less aggressive behavior than 6 year old boys. The cartoon $\mathrm{x}$ age interaction shows that the effect of prosocial cartoons on aggressive behavior was smaller for ten-year-old boys than six-yearold boys. This finding is aligned with past research that older children were more sensitive to prosocial media and showed less aggressive behaviors than younger children (Bukowski, 1990; Chambers \& Ascione, 1987; Gentile, Li, Khoo, Prot, \& Anderson, 2014; Johnson et al., 2013). Younger boys mainly focused on the main features of cartoon contents, while older children assimilated various information from dialogues, vocalizations and prosocial cartoon model actions, as described by previous study (Calvert, Huston, Watkins, \& Wright, 1982). Thus, 10-year-old boys might assimilate more information from prosocial media models than 6-year-old boys. In this regard, prosocial cartoon programs aimed at preventing aggressive boys' aggressive behavior should be appropriately applied to the 10-year-old boys.

\subsection{Empathy mediates the effects of prosocial cartoon on aggressive behavior}

Consistent with $\mathrm{H} 3$ described, namely that prosoial cartoon viewing increases empathy that in turn decreases aggressive behavior. This finding is in line with assumptions of the GLM and underscores the importance of the cognitive and affective routes (i.e., cognitive empathy \& affective empathy) in predicting how aggressive behavior is decreased by exposure to prosocial cartoons. The finding is consistent with prior literature that empathy is positively correlated with prosocial media use (Gentile et al., 2009; Greitemeyer, 2009; Happ, André, \& Steffgen, 2015; Salem, 2010). The possible explanation is that increased empathy remits aggressive behavior to a certain extent, especially when they watch prosocial cartoons. Empathy can enhance prosocial attitudes of gamers and reduce their aggression accordingly (Greitemeyer, Osswald, \& Brauer, 2010; Happ, Melzer, \& Steffgen, 2013). The mediation results further helps us understand how to aggrandize the positive effects of empathy and cartoons, as well as the application in the field of aggression prevention. One possible explanation is that the BES provides a basis for justifying the cartoon character's prosocial behavior, which makes aggressive boys being more prone to judge that the prosocial behavior of cartoon characters is is liked by others, and thus decreasing their aggression. Moreover, the separated age mediation analysis suggests that prosocial cartoons leads to higher levels of empathy, which, in turn, lead to a reduction in aggressive behavior among 10 year olds. Empathy is assessed to be positively related to age, but is negatively correlated with aggressive behavior. This finding indicates that empathy is a core factor which decreases aggression among 10 year olds 
after prosocial cartoon exposure. Therefore, empathy training should be encouraged as a prevention strategy to decrease aggression among boys nominated by teachers as aggressive.

\subsection{Strengths, limitations, and implications}

Although many studies have focused on the negative effects of screen violence on children and adolescents, few have focused on the cumulatively positive effects of prosocial cartoons on aggressive boys. The study has several strengths. First, the experimental-control design, randomization of participants and interesting age effects may allow us to draw causal inferences. This causality can be claimed as a strong point. Second, this study expands previous research by generalizing the prosocial cartoon effect to aggressive Chinese boys (non-Western sample). This study adds to the knowledge that watching prosocial cartoons (versus nonprosocial) decreases aggressive behavior among aggressive boys (especially 10 year olds). Although the study may not make a novel theoretical contribution, it does allow for an extension of existing research and a test of its generalizability to Eastern cultures. Third, the present study adopted 5 different exemplars of prosocial cartoons and 5 different exemplars of nonprosocial cartoons, which extends to the entire category of prosocial cartoons to generalize the results. The cartoon manipulation beyond previous research adopting a single prosocial media and a single nonprosocial media. Finally, the prosocial versus nonprosocial cartoon effect is mediated by increased empathy in aggressive boys (a special group) that up to date has received relatively little attention in China. This finding further proves the predictive validity of the GLM for the effects of prosocial media exposure on social outcomes through internal states (i.e., empathy).

However, several limitations should be emphasized. First, although the experimental data can provide causal evidences, they are necessarily limited to the short-term approach. Usually, boys watch cartoons several hours a day, several days a week, and many weeks-it can be assumed that the long-term cumulative experiences of watching cartoons will be associated with larger effect sizes. Experimental longitudinal research evidence with similar dependent variables may be obtained in the future, particularly with reference to learning how empathy may change aggressive behavior in a long run. Second, using self-report data for empathy measurement may not be objective. It may be useful for researchers to obtain reports from others (e. g., peers, parents, teachers). Third, although the finding replicates previous research that aggressive boys are sensitive to aggression in terms of age (6 years versus 10 years), the results of the present study offer only a partial picture of the situation by considering only aggressive boys. Fourth, although mediation analyses are used, it may be inappropriate to test mediation in data that is not longitudinal. The mediation results may not justify the causal nature of the paths being tested. Besides, only the intensity of noise used as the outcome may not be the best measure of aggression, it may be advisable to include a composite measure (intensity and duration) for identifying aggression for future research. In other words, we may consider a composite measure as more compelling in future operationalization of aggression to draw stronger conclusions.

The study has several theoretical and practical implications. First, watching prosocial (versus nonprosocial) cartoons increases levels of empathy which in turn decreases aggression, which supports the contentions of the GLM that the interaction between situational (i.e., cartoons) and personal factors 
(i.e., age) predicts aggressive behavior. Second, this is an experimental study that nicely complements previous research and has some important practical implications (i.e., how aggression can be decreased). Repeated exposure of aggressive boys to prosocial cartoons decreases aggressive behavior, indicating the importance of prosocial cartoons as a valid measure in decreasing aggression. In particular, the reducing effect is stronger among 10-year-old aggressive boys, and weaker among 6-year-old aggressive boys. The finding suggests that cartoon developers, parents and child psychologists should should especially use prosocial cartoons as an effective way to decrease aggression among 10-year-old aggressive boys. For example, we can improve children's screen experience through co-viewing cartoons with children (Meng et al., 2020). Finally, given that aggressive behavior can be decreased by increasing prosocial content of cartoons and levels of empathy, increasing prosocial cartoon exposure and empathy training programs may alleviate aggression for aggressive Chinese boys.

\section{Declarations}

\section{Conflicts of Interest}

The authors declare no conflicts of interest.

\section{Ethical Approval}

In Fall semester of 2019, this study was authorized by the Ethics Committee of researchers' University, Chongqing, China. This study was also approved by parents and teachers. All parents signed informed consents in accordance with the Declaration of Helsinki. Their consent rates account for $100 \%$.

\section{Informed Consent}

Informed consent was obtained from all parents of participants included in the study.

\section{Acknowledgments}

This work was supported by the National Social Science Foundation of China (17CSH006), the Grant of Chongqing University Teachers and students' Ideological and political work research and consultation center (20SZYZZD005), the Grant of Planned Social Sciences in Chongqing (2017YBJY085), and the Major Grant of Basic Education Quality Monitoring Collaborative Innovation Center in China (2020-06005-BZPK01). We thank the boys and teachers from kindergartens and primary schools who cooperated in this study.

\section{References}


1. Adachi, P. J. C., \& Willoughby, T. (2011). The effect of violent video games on aggression: Is it more than just the violence? Aggression and Violent Behavior, 16(1), 55-62.

https://doi.org/10.1016/j.avb.2010.12.002

2. Anderson, C. A., Anderson, K. B., \& Deuser, W. E. (1996). Examining an affective aggression framework weapon and temperature effects on aggressive thoughts, affect, and attitudes. Personality and Social Psychology Bulletin, 22(4), 366-376. https://doi.org/10.1177/0146167296224004

3. Anderson, C. A., Buckley, K. E., \& Carnagey, N. L. (2008). Creating your own hostile environment: A laboratory examination of trait aggressiveness and the violence escalation cycle. Personality and Social Psychology Bulletin, 34(4), 462-473. https://doi.org/10.1177/0146167207311282

4. Anderson, C. A., \& Bushman, B. J. (2002). Human aggression. Annual Review of Psychology, 53(1), 27-51. https://doi.org/10.1146/annurev.psych.53.100901.135231

5. Anderson, C. A., Shibuya, A., Ihori, N., Swing, E. L., Bushman, B. J., \& Sakamoto, A., Rothstein, H. R., \& Saleem, M. (2010). Violent video game effects on aggression, empathy, and prosocial behavior in Eastern and Western countries: A meta-analytic review. Psychological Bulletin, 136(2), 151-173. https://doi.org/10.1037/a0018251

6. Archer, J. (2009). Does sexual selection explain human sex differences in aggression?. Behavioral and Brain Sciences, 32(3-4), 266-267. https://doi.org/10.1017/S0140525X09990483

7. Bargh, J. A., Chen, M., \& Burrows, L. (1996). Automaticity of social behavior: direct effects of trait construct and stereotype-activation on action. Journal of Personality and Social Psychology, 71(2), 230-244. https://doi.org/10.1037/0022-3514.71.2.230

8. Barlett, C., Branch, O., Rodeheffer, C., \& Harris, R. (2009). How long do the short-term violent video game effects last?. Aggressive Behavior, 35(3), 225-236. https://doi.org/10.1002/ab.20301

9. Bartholow, B. D., Sestir, M. A., \& Davis, E. B. (2005). Correlates and consequences of exposure to video game violence: Hostile personality, empathy, and aggressive behavior. Personality and Social Psychology Bulletin, 31(11), 1573-1586. https://doi.org/10.1177/0146167205277205

10. Bickett, L. R., Milich, R., \& Brown, R. T. (1996). Attributional styles of aggressive boys and their mothers. Journal of Abnormal Child Psychology, 24(4), 457-472.

https://doi.org/10.1007/BF01441568

11. Boyle, E., Connolly, T. M., \& Hainey, T. (2011). The role of psychology in understanding the impact of computer games. Entertainment Computing, 2(2), 69-74.

https://doi.org/10.1016/j.entcom.2010.12.002

12. Buckley, K. E., \& Anderson, C. A. (2006). A theoretical model of the effects and consequences of playing video games. In P. Vorderer \& J. Bryant (Eds.), Playing video games: Motives, responses, and consequences (pp. 363-378). Routledge.

13. Bukowski, W. M. (1990). Age differences in children's memory of information about aggressive, socially withdrawn, and prosociable boys and girls. Child Development, 6(5), 1326-1334. https://doi.org/10.1111/j.1467-8624.1990.tb02864.x 
14. Bushman, B. J., \& Huesmann, L. R. (2006). Short-term and long-term effects of violent media on aggression in children and adults. Archives of Pediatric and Adolescent Medicine, 160(4), 348-352. https://doi.org/10.1001/archpedi.160.4.348

15. Calvert, S. L., Huston, A. C., Watkins, B. A., \& Wright, J. C. (1982). The relation between selective attention to television forms and children's comprehension of content. Child Development, 53(3), 601-610. https://doi.org/10.2307/1129371

16. Calvert, S. L., Murray, K. J., \& Conger, E. E. (2004). Heroic dvd portrayals: What us and taiwanese adolescents admire and understand. Journal of Applied Developmental Psychology, 25(6), 699-716. https://doi.org/10.1016/j.appdev.2004.09.004

17. Calvert, S. L., Strouse, G. A., \& Murray, K. J. (2006). Empathy for adolescents' role model selection and learning of DVD content. Journal of Applied Developmental Psychology, 27(5), 444-455. https://doi.org/10.1016/j.appdev.2006.06.005

18. Chambers, J. H., \& Ascione, F. R. (1987). The effects of prosocial and aggressive video games on children's donating and helping. The Journal of Genetic Psychology: Research and Theory on Human Development, 148 (4), 499-505. https://doi.org/10.1080/00221325.1987.10532488

19. Cuff, B. M. P., Brown, S. J., Taylor, L., \& Howat, D. J. (2016). Empathy: A review of the concept. Emotion Review, 8(2), 144-153. https://doi.org/10.1177/1754073914558466

20. Decety, J., Echols, S., \& Correll, J. (2010). The blame game: the effect of responsibility and social stigma on empathy for pain. Journal of Cognitive Neuroscience, 22(5), 985-997. https://doi.org/10.1162/jocn.2009.21266

21. Dillon, K. P., \& Bushman, B. J. (2017). Effects of exposure to gun violence in movies on children's interest in real guns. JAMA Pediatrics, 171(11), 1057-1062.

https://doi.org/10.1001/jamapediatrics.2017.2229

22. Dodge, K. A., \& Newman, J. P. (1981). Biased decision-making processes in aggressive boys. Journal of Abnormal Psychology, 90(4), 375-379. https://doi.org/10.1037/0021-843X.90.4.375

23. Farsides, T, Pettman, D., \& Tourle, L. (2013). Inspiring altruism: Reflecting on the personal relevance of emotionally evocative prosocial media characters. Journal of Applied Social Psychology, 43(11), 2251-2258. https://doi.org/10.1111/jasp.12175

24. Funk, J. B., Baldacci, H. B., Pasold, T., \& Baumgardner, J. (2004). Violence exposure in real-life, video games, television, movies, and the internet: Is there desensitization?. Journal of Adolescence, 27(1), 23-39. https://doi.org/10.1016/j.adolescence.2003.10.005

25. Gao, X., Pan, W., Li, C., Lei, W., Yao, M., \& Chen, A. (2017). Long-time exposure to violent video games does not show desensitization on empathy for pain: An fMRI study. Frontiers in Psychology, 8, 650. https://doi.org/10.3389/fpsyg.2017.00650

26. Geen, R. G. (2001). Human aggression (2nd ed.). Taylor \& Francis.

27. Gentile, D. A., Anderson, C. A., Yukawa, S., Saleem, M., Lim, K. M., Shibuya, A., \& Sakamoto, A. (2009). The effects of prosocial video games on prosocial behaviors: International evidence from 
correlational, longitudinal, and experimental studies. Personality and Social Psychology Bulletin, 35(6), 752-763. https://doi.org/10.1177/0146167209333045

28. Gentile, D. A., Bender, P. K., \& Anderson, C. A. (2017). Violent video game effects on salivary cortisol, arousal, and aggressive thoughts in children. Computers in Human Behavior, 70(5), 39-43. https://doi.org/10.1016/j.chb.2016.12.045

29. Gentile, D. A., Li, D., Khoo, A., Prot, S., \& Anderson, C. A. (2014). Mediators and moderators of longterm effects of violent video games on aggressive behavior: Practice, thinking, and action. JAMA Pediatrics, 168(5), 450-457. https://doi.org/10.1001/jamapediatrics.2014.63

30. Graham, S., Weiner, B., \& Benesh-Weiner, M. (1995). An attributional analysis of the development of excuse giving in aggressive and nonaggressive African American boys. Developmental Psychology, 31(2), 274-284. https://doi.org/10.1037/0012-1649.31.2.274

31. Greitemeyer, T. (2013). Playing video games cooperatively increases empathetic concern. Social Psychology, 44(6), 408-413. https://doi.org/10.1027/1864-9335/a000154

32. Greitemeyer, T. (2011). Effects of prosocial media on social behavior: When and why does media exposure affect helping and aggression? Current Directions in Psychological Science, 20(4), 251255. https://doi.org/10.1177/0963721411415229

33. Greitemeyer, T. (2009). Effects of songs with prosocial lyrics on prosocial thoughts, affect, and behavior. Journal of Experimental Social Psychology, 45(1), 186-190. https://doi.org/10.1016/j.jesp.2008.08.003

34. Greitemeyer, T., Agthe, M., Turner, R., \& Gschwendtner, C. (2012). Acting prosocially reduces retaliation: Effects of prosocial video games on aggressive behavior. European Journal of Social Psychology, 42(2), 235-242. https://doi.org/10.1002/ ejsp.1837

35. Greitemeyer, T., \& Mügge, D. O. (2014). Video games do affect social outcomes: A meta-analytic review of the effects of violent and prosocial video game play. Personality and Social Psychology Bulletin, 4O(5), 578-589. https://doi.org/10.1177/ 0146167213520459

36. Greitemeyer, T., \& Osswald, S. (2009). Prosocial video games reduce aggressive cognitions. Journal of Experimental Social Psychology, 45(4), 896-900. https://doi.org/10.1016/j. jesp.2009.04.005

37. Greitemeyer, T., Osswald, S., \& Brauer, M. (2010). Playing prosocial video games increases empathy and decreases schadenfreude. Emotion, 10(6), 796-802. https://doi.org/10.1037/a0020194

38. Happ, C., Melzer, A., \& Steffgen, G. (2015). Like the good or bad guy-empathy in antisocial and prosocial games. Psychology of Popular Media Culture, 4(2), 80-96. https://doi.org/10.1037/ppm0000021

39. Happ, C., Melzer, A., \& Steffgen, G. (2013). Superman vs. bad man? the effects of empathy and game character in violent video games. Cyberpsychology, Behavior, and Social Networking, 16(10), 774778. https://doi.org/10.1089/cyber.2012.0695

40. Hartmann, T., Toz, E., \& Brandon, M. (2010). Just a game? unjustified virtual violence produces guilt in empathetic players. Media Psychology, 13(4), 339-363.

https://doi.org/10.1080/15213269.2010.524912 
41. Hayes, A. F. (2013). Introduction to mediation, moderation, and conditional process analysis. Journal of Educational Measurement, 51(3), 335-337. https://doi.org/10.1111/jedm.12050

42. Hemovich, V. (2020). It does matter if you win or lose, and how you play the (video) game.

43. Games and Culture, online publication. https://doi.org/10.1177/1555412020913760

44. Johnson, C., Heath, M. A., Bailey, B. M., Coyne, S. M., Yamawaki, N., \& Eggett, D. L. (2013). Adolescents' perceptions of male involvement in relational aggression: Age and gender differences. Journal of School Violence, 12(4), 357-377. https://doi.org/10.1080/15388220.2013.819557

45. Jolliffe, D., \& Farrington, D. P. (2006). Development and validation of the basic empathy scale. Journal of Adolescence, 29(4), 589-611. https://doi.org/10.1016/j.adolescence.2005.08.010

46. Kennedy, P. E. (2013). The relationship between prosocial music and helping behaviour and its mediators: An Irish college sample. Journal of European Psychology Students, 43(2), 55-62. https://doi.org/10.1111/1468-5884.00160

47. Kirsh, S. J. (2006). Cartoon violence and aggression in youth. Aggression and Violent Behavior, 17(6), 547-557. https://doi.org/10.1016/j.avb.2005.10.002

48. Klimecki, O. M., Mayer, S. V, Jusyte, A., Schee, J., \& Schönenberg, M. (2016). Empathy promotes altruistic behavior in economic interactions. Scientific Reports, 6, 31961.

https://doi.org/10.1038/srep31961

49. Konzok, J., Kreuzpointner, L., Henze, G. I., Wagels, L., \& Kudielka, B. M. (2020). Validation of a monetary Taylor aggression paradigm: Associations with trait aggression and role of provocation sequence. Journal of Experimental Social Psychology, 88(1), 103960.

https://doi.org/10.1016/j.jesp.2020.103960

50. Liss, M. B., \& Reinhardt, L. C. (1980). Aggression on prosocial television programs. Psychological Reports, 46(3), 1065-1066. https://doi.org/10.2466/pr0.1980.46.3c.1065

51. Lockwood, P., \& Viding, E. (2016). Commentary: conduct disorder and perceiving harm to others-a reflection on Michalska etal. (2016). Journal of Child Psychology and Psychiatry 57(4), 520-522. https://doi.org/10.1111/jcpp.12528

52. Luther, C. A., \& Legg, J. R. (2010). Gender differences in depictions of social and physical aggression in children's television cartoons in the US. Journal of Children and Media, 4(2), 191-205. https://doi. org/10.1080/17482791003629651

53. Meng, Q., Sheng, X., Zhao, J., Wang, Y., \& Su, Z. (2020). Influence of mothers/grandmothers coviewing cartoons with children on children's viewing experience. Frontiers in Psychology, 11, 1232. https://doi.org/10.3389/fpsyg.2020.01232

54. Miller, P. A., \& Eisenberg, N. (1988). The relation of empathy to aggressive and externalizing/antisocial behavior. Psychological Bulletin, 103(3), 324-344. https://doi.org/10.1037/0033-2909.103.3.324

55. Prescott, A. T., Sargent, J. D., \& Hull, J. G. (2018). Metaanalysis of the relationship between violent video game play and physical aggression over time. Proceedings of the National Academy of 
Sciences of the United States of America, 115(40), 9882-9888.

https://doi.org/10.1073/pnas.1611617114

56. Prot, S., Gentile, D. A., Anderson, C. A., Suzuki, K., Swing, E., Lim, K. M., \& Lam, B. P. (2014). Long-term relations among prosocial-media use, empathy, and prosocial behavior. Psychological Science, 25(2), 358-368. https://doi.org/10.1177/0956797613503854

57. Qin, Y. Y. (2004). The influence of aggressive behavior on peer relationship in middle childhood. Doctoral Dissertation Thesis, Central China Normal University, Wuhan, Hubei, China.

58. Saleem, M., Anderson,C. A., \& Gentile, D. A. (2012). Effects of prosocial, neutral, and violent video games on children's helpful and hurtful behaviors. Aggressive Behavior, 38(4), 281-287. https://doi.org/10.1002/ab.21428

59. Salem, S. K. (2010). The effects on pro-social video games on empathy. Master's thesis. California State University, Chico.

60. Smith, P., \& Waterman, M. (2005). Sex differences in processing aggression words using the emotional stroop task. Aggressive Behavior, 31(3), 271-282. https://doi.org/10.1002/ab.20071

61. Szycik, G. R., Bahram, M., Münte T. F., \& Te, W. B. T. (2017). Lack of evidence that neural empathic responses are blunted in excessive users of violent video games: An fMRI study. Frontiers in Psychology, 8, 174. https://doi.org/10.3389/fpsyg.2017.00174

62. Tan, X. Q. (2005). The influence of relational aggression on children's peer relationship in middle childhood. Master's Thesis, Central China Normal University, Wuhan, HuBei, China.

63. Tear, M. J., \& Nielsen, M. (2014). Video games and prosocial behavior: A study of the effects of nonviolent, violent and ultra-violent gameplay. Computers in Human Behavior, 41(12), 8-13. https://doi.org/10.1016/j.chb.2014.09.002

64. Teng, Z. J., Nie, Q., Zhu, Z. H., \& Guo, C. (2020). Violent video game exposure and (cyber) bullying perpetration among Chinese youth: The moderating role of trait aggression and moral identity. Computers in Human Behavior, 104(3), 106193. https://doi.org/10.1016/j.chb.2019.106193

65. Toldos, M. P. (2010). Sex and age differences in self-estimated physical, verbal and indirect aggression in Spanish adolescents. Aggressive Behavior, 31(1), 13-23. https://doi.org/10.1002/ab.20034

66. Warburton, W. A., \& Bushman, B. J. (2019). The competitive reaction time task: The development and scientific utility of a flexible laboratory aggression paradigm. Aggressive Behavior, 45 (4), 389-396. https://doi.org/10.1002/ab.21829

67. Whitaker, J. L., \& Bushman, B. J. (2012). "Remain calm. Be kind." Effects of relaxing video games on aggressive and prosocial behavior. Social Psychological and Personality Science, 3(1), 88-92. https://doi.org/10.1177/1948550611409760

68. Zhang, Y. X. (2016). Gender differences in the development of aggressive behavior in middle and late childhood and its impact on peer relationship. Master's Thesis, Central China Normal University, Wuhan, Hubei, China. 
69. Zhao, Z. (2018). A study on the relationship between inhibition control and aggressive behavior in 36-year-old children. Master's Thesis, Tianjin Normal University, China.

70. Zhen, S. J., Xie, H. L., Zhang, W., Wang, S. J., \& Li, D. P. (2011). Exposure to violent computer games and Chinese adolescents' physical aggression: The role of beliefs about aggression, hostile expectations, and empathy. Computers in Human Behavior, 27(5), 1675-1687. https://doi.org/10.1016/j.chb.2011.02.006

\section{Figures}

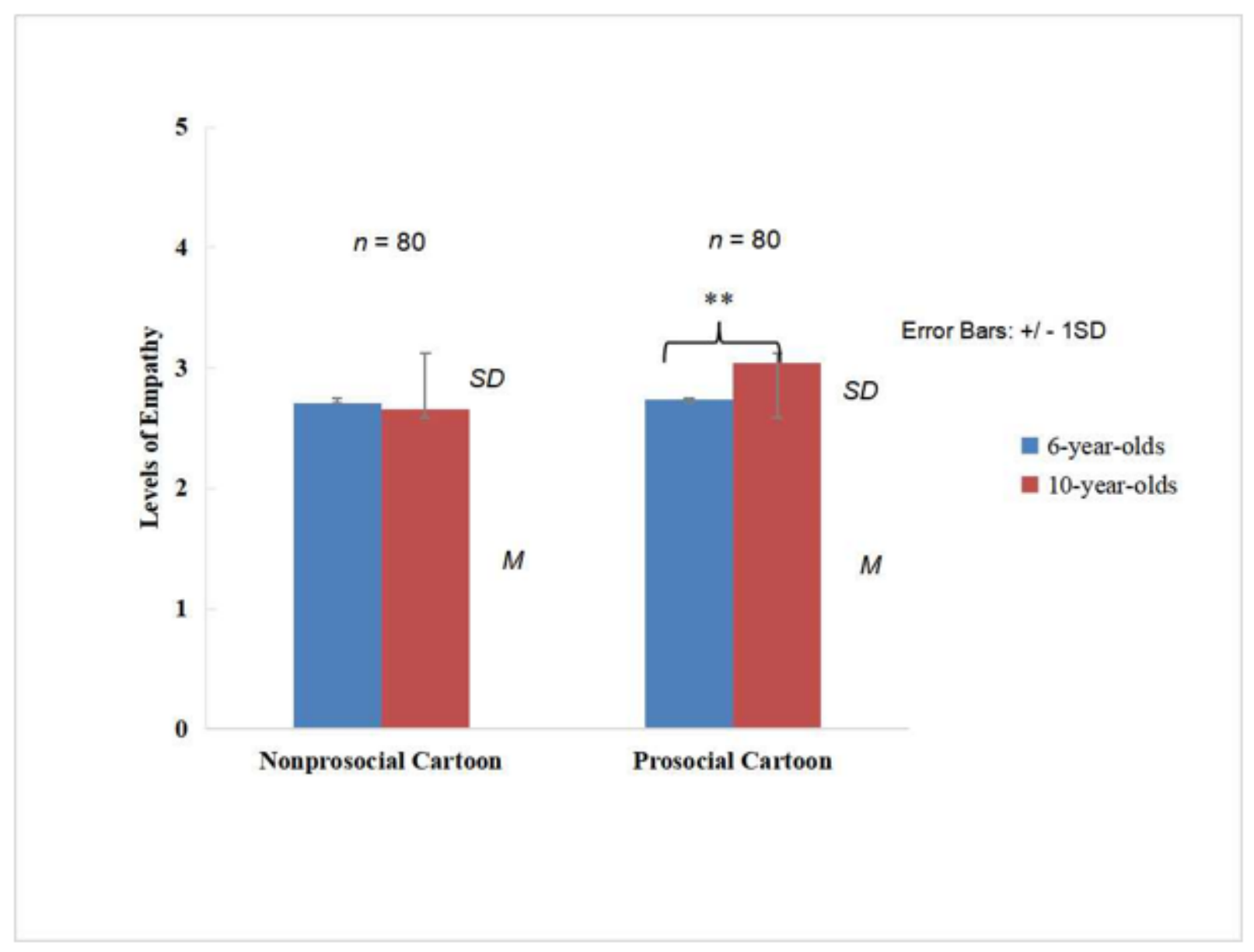

\section{Figure 1}

Cartoon $x$ age interaction on levels of empathy. Error bars represent standard deviations. ${ }^{\star *} p<0.01$. 


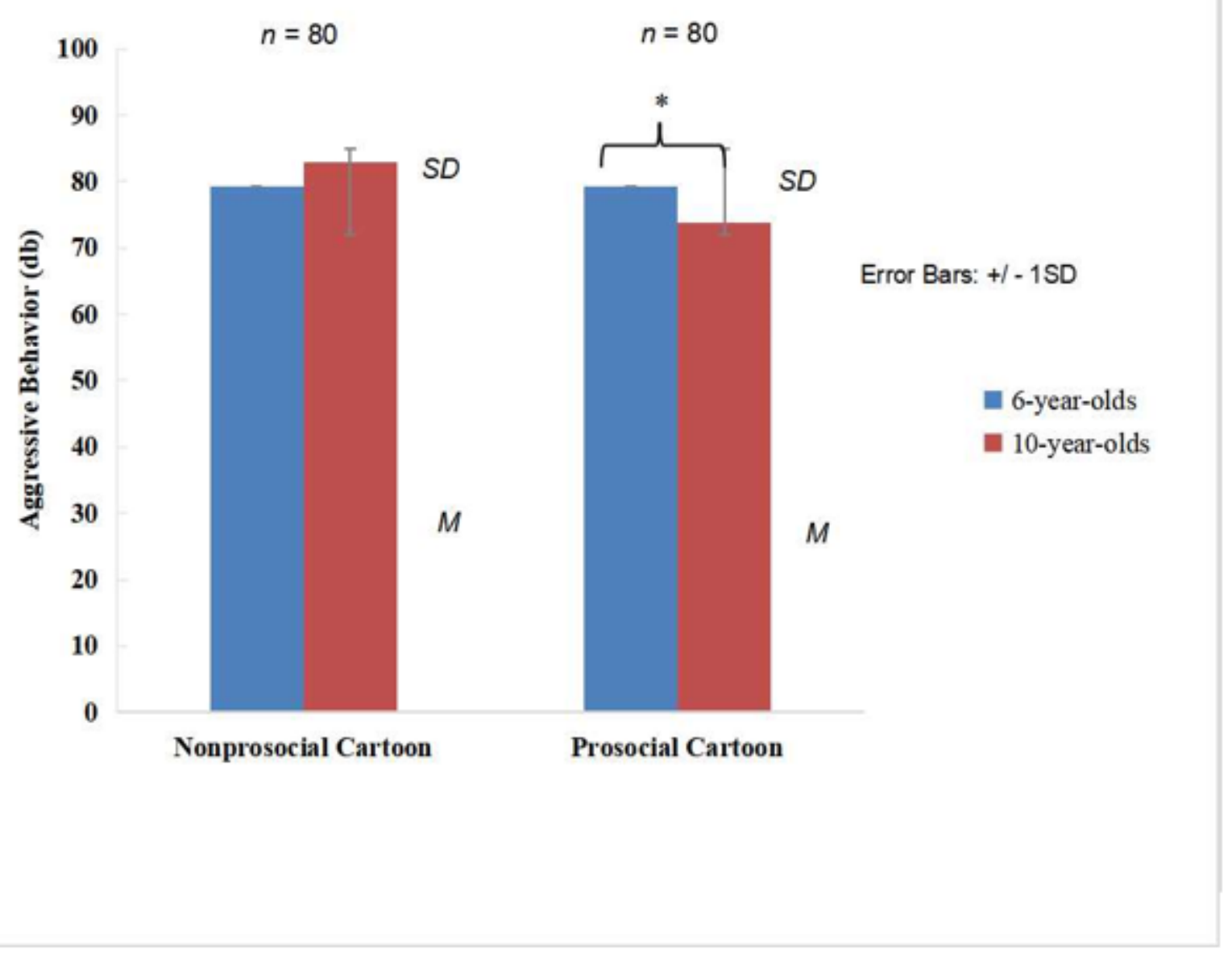

Figure 2

Cartoon $\mathrm{x}$ age interaction on aggressive behavior. Error bars represent standard deviations. ${ }^{\star} p<0.05$.

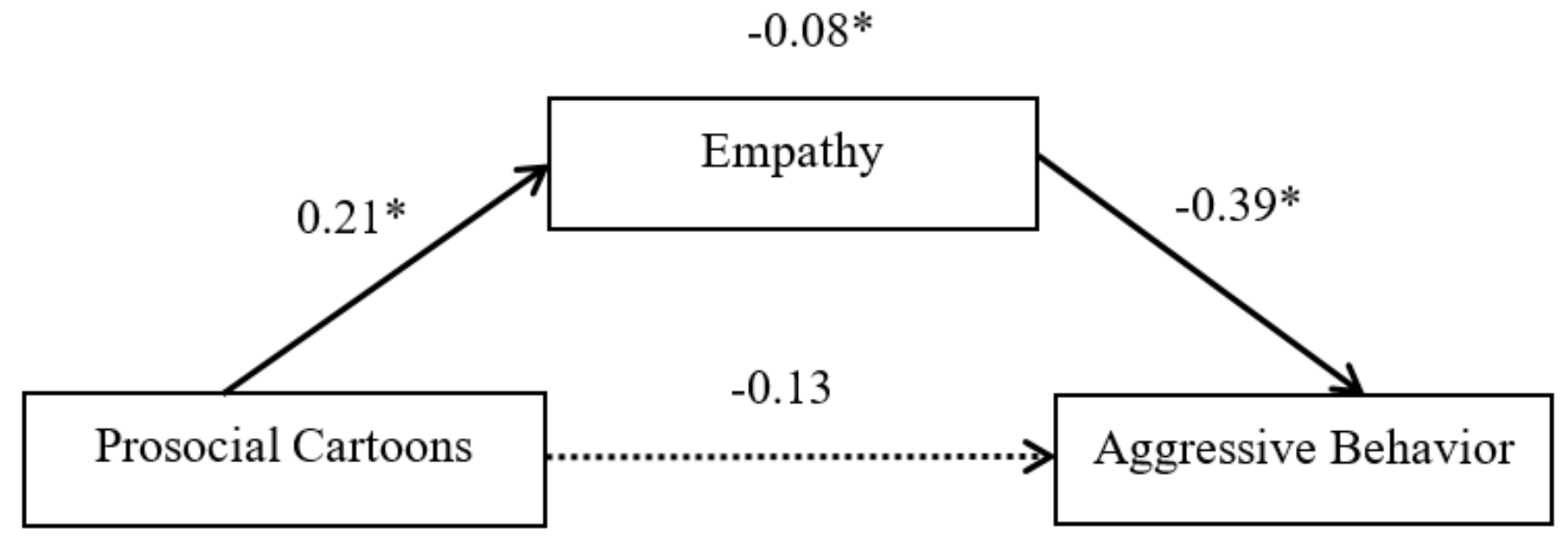

Figure 3

Mediation model of prosocial cartoons on aggressive behavior through empathy. Note: $1=$ prosocial, $0=$ nonprosocial; Standardized path coefficients are shown; Solid lines represent significant paths, dashed 
line represents a non-significant path. ${ }^{\star} p<0.05$.

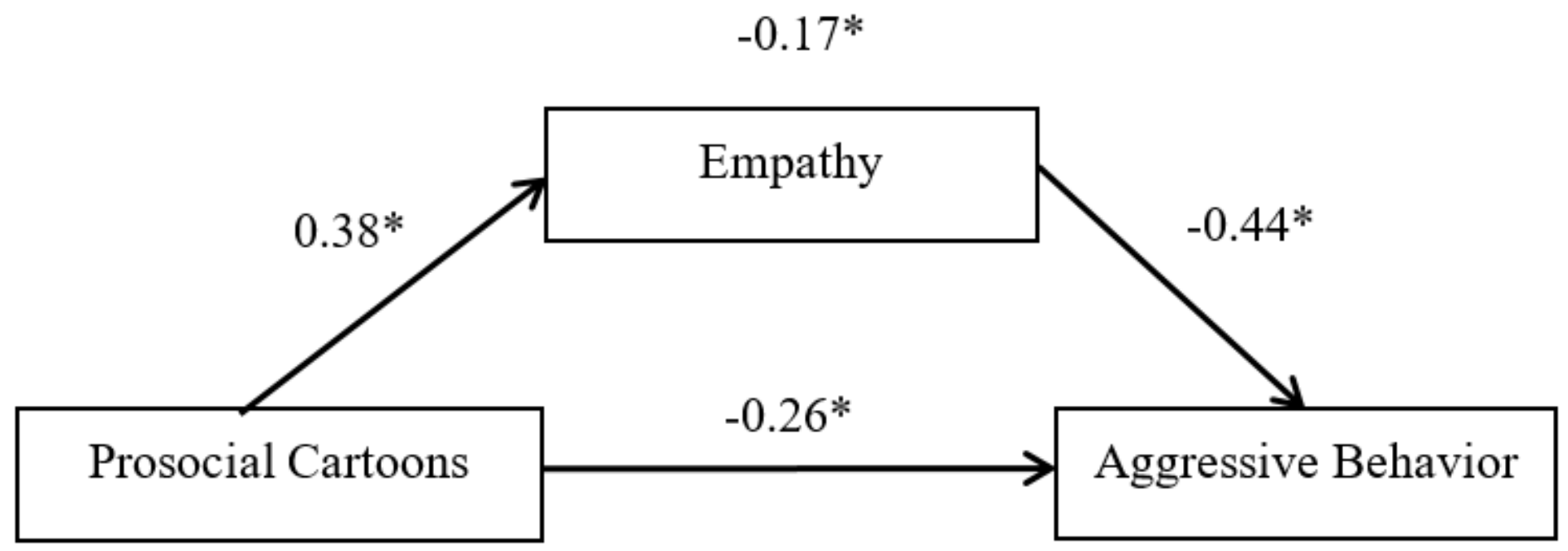

\section{Figure 4}

Partial mediation model of prosocial cartoons on aggressive behavior through empathy for 10-year-old aggressive boys. Note: 1 = prosocial, 0 = nonprosocial; Standardized path coefficients are shown; Solid lines represent significant paths. ${ }^{*} p<0.05$. 